\title{
The acute effect of lower-body training on average power output measured by loaded half-squat jump exercise
}

\author{
Matúš Krčmár*, Jaromír Šimonek, and Ivan Vasilovský \\ Faculty of Education, Constantine the Philosopher University in Nitra, Nitra, Slovakia
}

Copyright: (C) 2015 M. Krčmár et al. This is an open access article licensed under the Creative Commons Attribution License (http://creativecommons.org/licenses/by/4.0/).

\begin{abstract}
Background: High muscular power output is required in many athletic endeavors in order for success to be achieved. In the scientific community postactivation potentiation and its effect on performance are often discussed. There are many studies where the effect of resistance exercise on motor performance (such as vertical jump performance and running speed) has been investigated but only a few of them studied power output. Objective: The purpose of this study was to determine the acute responses to a 2 set loaded half-squat jumps and 2 set loaded back half-squat protocols designed to induce the acute maximum average power output during loaded half-squat jumps. Methods: A randomized cross-over design was used. 11 participants of this study performed 3 trials in randomized order separated by at least 48 hours where maximum average power output was measured. The specific conditioning activities were comprised of 2 sets and 4 repetitions of half-squat jumps, 2 sets and 4 repetitions of back half-squat exercises and a control protocol without an intervention by specific a conditioning activity. Participants were strength trained athletes with different sport specializations (e.g. ice-hockey, volleyball). Mean age of the athletes was $22 \pm 1.8$ years, body mass $80 \pm 7.1 \mathrm{~kg}$ and body height $185 \pm 6.5 \mathrm{~cm}$. Analysis of variance with repeated measures was used to determine differences between pre- and post-condition in each protocol, as well as between conditioning protocols, and also effect size was used to evaluate practical significance. Results: Maximum average power was significantly enhanced after application of the half-squat jump condition protocol $(1496.2 \pm 194.5$ to $1552 \pm 196.1 \mathrm{~W}, \Delta \sim 3.72 \%, p<.001$ ) and after application of the back half-squat protocol (1500.7 \pm 193.2 to $1556 \pm 191.2 \mathrm{~W}, \Delta \sim 3.68 \%, p<.001)$ after $10 \mathrm{~min}$ of rest. Power output after control protocol was significantly decreased $(1516.7 \pm 221.8$ to $1506.9 \pm 231.1 \mathrm{~W}$, $\Delta \sim 0.64 \%, p=.02$ ) after 10 min of rest. Conclusions: It appears that using this type of exercise with individualized external load could be a useful method to enhance average power output in training of athletes in a variety of sports with regards to their training background.
\end{abstract}

Keywords: acute effect, half-squat jump, back half-squat, power enhancement, power

\section{Introduction}

High muscular power output is required in many athletic endeavors in order for success to be achieved (Baker, 2001a). Therefore, strength and conditioning coaches search for ways to elicit gains in the power generated by their athletes. There are training programs aiming to enhance power through resistance training (Newton, Kraemer, \& Hakkinen, 1999), plyometric training (Kyröläinen et al., 2005) and combination of both (Duthie, Young, \& Aitken, 2002; Fatouros et al., 2000).

\footnotetext{
* Address for correspondence: Matúš Krčmár, Department of Physical Education and Sport, Faculty of Education, Constantine the Philospher University in Nitra, Tr. A. Hlinku 1, 94974 Nitra, Slovakia. E-mail: matus.krcmar@ukf.sk
}

Currently in sport and in the scientific community postactivation potentiation (PAP) and its effect on sport performance has often been discussed. Mechanism of PAP is based on phosphorylation of regulatory light chains myosin and neural excitability (Jeffreys, 2008). Rassier and Macintosh (2000) assume that mechanism responsible for PAP is based on phosphorylation of regulators of light chains myosin and muscle stimulation causes increase in sarcoplasmic $\mathrm{CA}^{2+}$ which activates myosin light chain kinase and thus this way actin-myosin cross-bridges with increased supplies of adenosine triphosphate could be increased. This suggestion is in line with Paasuke, Ereline, and Gapeyevea (1996) who argue that the mechanism responsible for PAP is based on phosphorylation of regulators of light chains myosin. There is also a discussion about 
possible changes in pennation angle (Tillin \& Bishop, 2009).

There are many factors that influence whether the conditioning exercise will enhance performance, including training background, experience in strength training, type of muscle fibers, exercise selection, rest interval between sets and time of rest after conditioning exercise to performance exercise (Seitz, de Villarreal, \& Haff, 2014; Wilson et al., 2013).

There are several studies examining acute responses to resistance exercise through high load resistance, for example in the study by Chatzopoulos et al. (2007) participants performed $10 \times 1 \times 90 \% 1 \mathrm{RM}$ and after conditioning program they enhanced running time on $30 \mathrm{~m}$ sprint $(p=.05)$ after $5 \mathrm{~min}$ of rest. In the study by McCann and Flanagan (2010) found that volleyball players who performed $5 \times 5 \mathrm{RM}$ back squat and $5 \times 5 \mathrm{RM}$ hang clean and after both exercises enhanced countermovement vertical jump performance $(+2.72 \pm 1.21 \mathrm{~cm} ; p<.01)$ after 4 min of rest. There are also studies where power output through power oriented exercises was examined. In the studies by Baker (2003) and Bevan, Owen, Cunnigham, Kingsley, and Kilduff (2009) acute responses of bench press and bench press throw to the enhancement of maximal power output were examined. In both studies power output increased. In the study by Baker (2003) it occurred after $3 \mathrm{~min}(+4.5 \%)$, and in the study of Bevan et al. (2009) after 8 min.

Wilson et al. (2013) designed meta-analysis on the basis of 32 studies dealing with PAP. Their results suggest that optimal external load to elicit PAP ranges between $60-84 \%$ 1RM, optimal interval of rest lies within the range of 7-10 min. Moreover, they found significant differences between trained and untrained individuals. Seitz et al. (2014) examined whether stronger individuals are able to achieve PAP effect earlier in comparison with weaker individuals. Their results show that stronger individuals reached potentiation within the range of 3-12 min and weaker ones within 6-12 min. It seems that optimal rest interval, external load and training background of individuals have an effect on PAP and also whether the PAP effect occurs at all.

There are only few studies examining the acute responses to induce power output and especially the ones studying maximum average power.

The importance of average power output according to study by Miyaguchi and Demura (2008) may lie in the fact that degree of stretch-shortening cycle (SSC) may enhance power output $(200-780 \%$ in the first 100 milliseconds). Authors found high correlation $(r=.70)$ between eccentric maximum strength and peak power output and this parameter did not correlate with the initial power output in the first 100 milliseconds during elbow flexion in SSC conditions. Authors suggest that it raises importance to measure not only peak power but also average power output from entire range of motion.

Therefore, the purpose of the present study was to determine the acute responses to a 2 sets and 4 repetitions of loaded half-squat jump protocol and 2 sets and 4 repetitions of loaded half back-squat protocol designed to enhance the acute maximum average power output in strength trained athletes. From a practical point of view we wanted to find out if it is possible to enhance average power output when it is known that external load is lighter when peak power output is maximized in comparison with external load when average power is measured (Zemková et al., 2014).

\section{Methods}

\section{Participants}

Eleven strength trained athletes volunteered to take part in this study. The sample comprised 6 ice-hockey players, 3 volleyball players (women), 1 rower and 1 karateist. Mean age of participants was $22 \pm 1.8$ years, body mass $80 \pm 7.1 \mathrm{~kg}$, and body height $185 \pm 6.5 \mathrm{~cm}$. Prior to the study, athletes were fully informed about study and possible risks were explained. They signed an informed consent form. All participants had at least 4 years' experiences with strength training. The study was approved by the local ethics committee and it was performed according to the Declaration of Helsinki.

\section{Measurements}

Power testing

One week before the intervention of the experimental stimuli, the participants performed a diagnostic series of loaded half-squat jumps to determine the optimal external load that maximize maximum average power of each participant. Subjects performed half-squat jumps with a barbell on the shoulders. Diagnostic series began with a load of $20 \mathrm{~kg}$ and gradually increased in $10 \mathrm{~kg}$ steps until maximum average power was recorded and no longer increased (Hamar, Gažovič, \& Schickhofer, 1998). A two-minute-long rest between attempts was included. After completion of the diagnostic series 8 min active rest (slow walking) after which subjects realized 8 repetitions of half-squat jumps in succession without stopping at the bottom of the movement was included. Weight of the barbell was determined according to previously established barbell mass where maximum average power in concentric phase of movement was recorded. In this testing we tried to find out the number of repetitions which subjects were able to hold 
on above $90 \%$ of maximum average power (Figure 1 ). The squat depth was controlled by the use of foam cubes for proper squat depth $\left(90^{\circ}\right.$ knee angle) (Figure 2). Average power in concentric phase of movement was measured using a linear position transducer (LPT) Tendo Power Weightlifting Analyzer (TWA) (Tendo Sports Machines, Trencin, Slovak Republic). The device consists of sensor unit with durable kevlar cable which was attached to the barbell grip to measure displacement. The TWA unit was placed on the floor in a position that would allow the cord to be extended

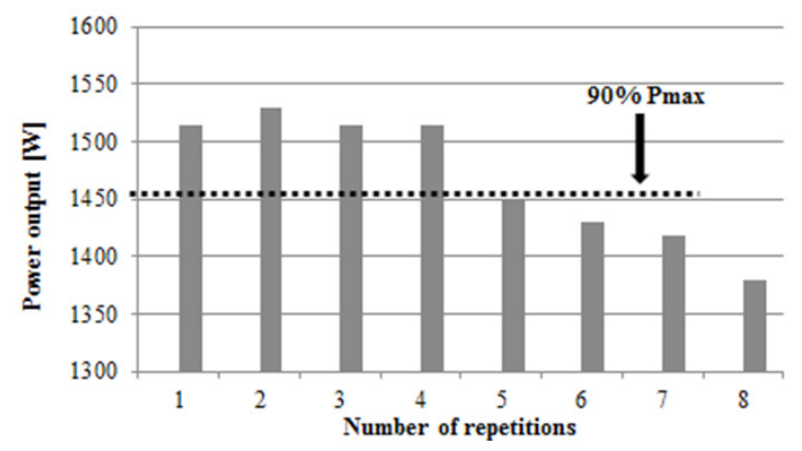

Figure 1. Average number of repetitions above $90 \%$ of maximum average power (Pmax) during half-squat jumps with barbell load equal to Pmax reached in diagnostic series

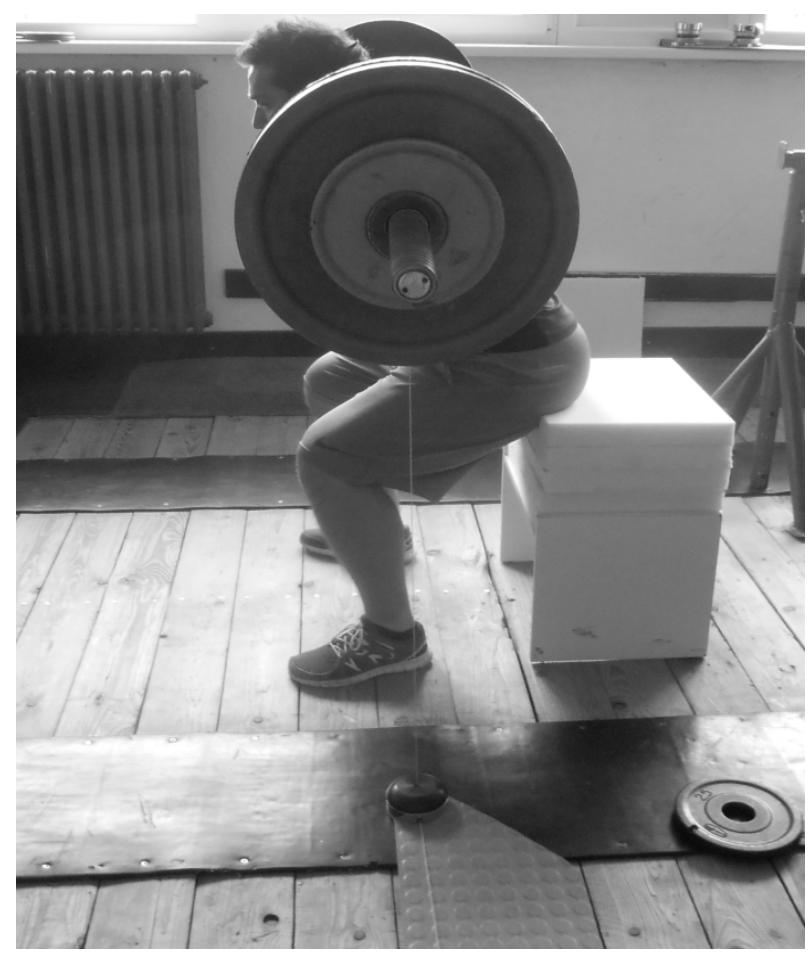

Figure 2. Individually adjusted foam cubes to control the range of motion $\left(90^{\circ}\right.$ in knee joint) and placement of the Tendo Power Weightlifting Analyzer on the floor and attachment via kevlar cord to the Olympic barbell perpendicular to the floor during the half-squat jump exercise in accordance with the manufacturer's User Guide (Tendo Power Analyzer Weightlifting: User's Guide, 2014). Sensor unit is connected to computer with associated software which gives feedbacks regarding velocity $\left(\mathrm{m} \cdot \mathrm{s}^{-1}\right)$, force $(\mathrm{N})$ and power $(\mathrm{W})$. According to Garnacho-Castaño, López-Lastra, and MatéMuñoz (2015) TWA is a reliable device to measure maximum average power $($ ICC $=.922-.988)$.

\section{Four repetition maximum testing}

In the next session there was a task to determine four repetition maximum (4RM) in back half-squat in the course of 3 days from power testing. The testing was performed in accordance with National Strength and Conditioning Association (NSCA) 1RM testing protocol (Baechle \& Earle, 2000). Range of motion in the knee joint $\left(90^{\circ}\right)$ was controlled by foam cubes similarly as in the previous testing. 4RM was determined as the resistive protocol based on the previous research which indicated that this condition stimulus was effective in enhancing lower body power and lowering injury risk in comparison with 1RM (Dohoney, Chromiak, Lemire, Abadie, \& Kovacs, 2002; Radcliff \& Radcliff, 1996). For determining the initial barbell mass to avoid frequent repetition of the test results of the previous diagnostic series were used.

Standardized warm-up, the same as in experimental and control protocol (see below in procedures), was performed in both power and 4RM testing sessions.

According to results of power and 4RM testing session weight of barbell was set individually for each participant. The determined maximum average power in the group after diagnostic series was $1520 \pm 192 \mathrm{~W}$ which corresponded to barbell load $83.6 \pm 17.2 \mathrm{~kg}$ and the average value of barbell load after 4RM testing session was $137.3 \pm 20.9 \mathrm{~kg}$. The overall mass of the system comprised the body mass of the participants and the barbell mass. According to the study by Cormie, McBride, and McMaulley (2007) body mass is a primary component of the force contributing to the calculation of power during lower-body movement (e.g. jump squats).

\section{Procedures}

A randomized cross-over design was used in the study, where participants performed experimental and control sessions. The experimental sessions included 2 series of 4 half-squat jumps and 2 series of 4RM back half-squats performed in a separate occasions. The control session consisted of standardized warm-up procedure followed by active rest interval (slow walking). The depth of the half-squat jumps and back half-squats 
was controlled by foam cubes $\left(90^{\circ} \mathrm{knee}\right.$ angle) in every testing session.

Before intervention of experimental or control conditioning activity subjects performed standardized warm-up. Warm-up consisted of 5 min slow running followed by $8 \mathrm{~min}$ dynamic stretching, then participants performed 1 series and 8 repetitions of half-squat jumps and 1 series of back half-squat with weight of barbell equal to half of body mass of each participant. Rest interval between sets was 1 min. 2 min after standardized warm-up the pre-testing began. Each participant performed 3 repetitions of half-squat jumps with barbell load set at the maximum average power recorded during diagnostic series. Three repetitions of half-squat jumps in each post-testing time points were performed. After pre-testing, 2 min rest was incorporated and 2 sets of 4 repetitions of half-squat jumps and 2 sets of 4RM back half-squats in separate occasions were performed, or they continued active rest (slow walking) lasting $6 \mathrm{~min}$ - control condition (totally $11 \mathrm{~min}$ ). The duration of experimental protocols was six minutes of experimental stimulus plus 5 min of rest until the first post-testing began. The rest between sets was $3 \mathrm{~min}$ and the time between completion of experimental protocols and the first post-testing was $5 \mathrm{~min}$, while the second post-testing was done 10 min after completion of experimental protocols. In the course of the whole experiment subjects were instructed to perform the eccentric phase in a controlled manner and then powerfully jump "as high as possible". Figure 3 shows schematic illustration of testing procedure. The parameter which we monitored was the highest maximum average power output recorded from 3 repetitions of half-squat jumps in succession.

Whole study comprising power testing, 4RM testing, experimental and control sessions was completed within 2 and a half weeks, while 3 days of rest was observed between individual sessions which followed recommended 48 hour long protocols, necessary for muscle recovery (Baechle \& Earle, 2000). Participants were asked to avoid any training intervention focused on maximum strength and power and refrain from training or demanding physical activity 48 hours prior to testing. The ingestion of ethyl alcohol and caffeine were forbidden for 24 and 3 hours before every testing session, respectively.

\section{Statistical analysis}

To evaluate significant differences between pre and post-testing in each experimental and control protocols ANOVA with repeated measures (1 group $\times 3$ condition $\times 3$ time) was used. Differences between experimental and control conditions were also evaluated using ANOVA. Bonferroni post hoc test was used to identify where significant differences occurred between pre and post-condition and between individual testing sessions. The alpha level of .05 was considered significant. All descriptive statistics and methods were evaluated using Statistica (Version 10; Statsoft, Tulsa, OK, USA). Effect size (ES; partial eta-squared - $\eta_{\mathrm{p}}^{2}$ ) was calculated to determine practical significance of results. According to Cohen (1988) the value of .10 is a small, .25 is a medium, and $>.40$ is a large effect. An intra-class correlation coefficient was calculated for each treatment to examine reliability of maximum average power. Normality of distribution through ShapiroWilk test was also calculated.

\section{Results}

Intra-class correlation coefficient was calculated to verify the reliability of maximum average power measurement and significant relationship was observed between maximum average power values in all pretesting sessions $(I C C=.977)$. Normality of data distribution was fulfilled.

Significant time $\times$ condition interaction $(F=8.957$, $p<.001, \eta_{\mathrm{p}}^{2}=.47$, power $\left.=.999\right)$ for the maximum average power output was observed.

Significant differences $(F=42.769, \quad p<.001$, $\eta_{\mathrm{p}}^{2}=.81$, power $=1.00$ ) after performing half-squat jump conditioning protocol occurred. Post hoc tests revealed that in the first post-testing ( $5 \mathrm{~min}$ ) no significant differences occurred $(p=.127,95 \%$ confidence interval $[-30.076,2.804])$ but in the second post-testing (10 $\mathrm{min})$ significant differences were recorded $(p<.001,95 \%$ confidence interval $[-72.258$, -39.377]). Comparison between the 1st and the 2nd post-testing showed significant differences $(p<.001$, $95 \%$ confidence interval $[-58.622,-25.741]$ ) (see Table 1 for values).

Significant differences $(F=52.137, \quad p<.001$, $\eta_{\mathrm{p}}^{2}=.83$, power $\left.=1.00\right)$ after performing back halfsquat conditioning protocol were recorded. Post-hoc tests revealed that in the first post-testing $(5 \mathrm{~min})$ no significant differences occurred ( $p=.218,95 \%$ confidence interval $[-26.182,4.182])$ but in the second post-testing (10 min) significant differences were recorded $(p<.001,95 \%$ confidence interval [-71.182, -40.817]). Comparison between the 1st and the 2nd post-testing showed significant differences $(p<.001$, 95\% confidence interval $[-60.182,-29.817]$ ) (see Table 1 for values).

After performing the control protocol significant differences $\left(F=5.226, p=.014, \eta_{p}^{2}=.34\right.$, power $\left.=.769\right)$ were recorded. Post hoc tests revealed that in the first post-testing ( $5 \mathrm{~min}$ ) no significant differences occurred 
$13 \min$

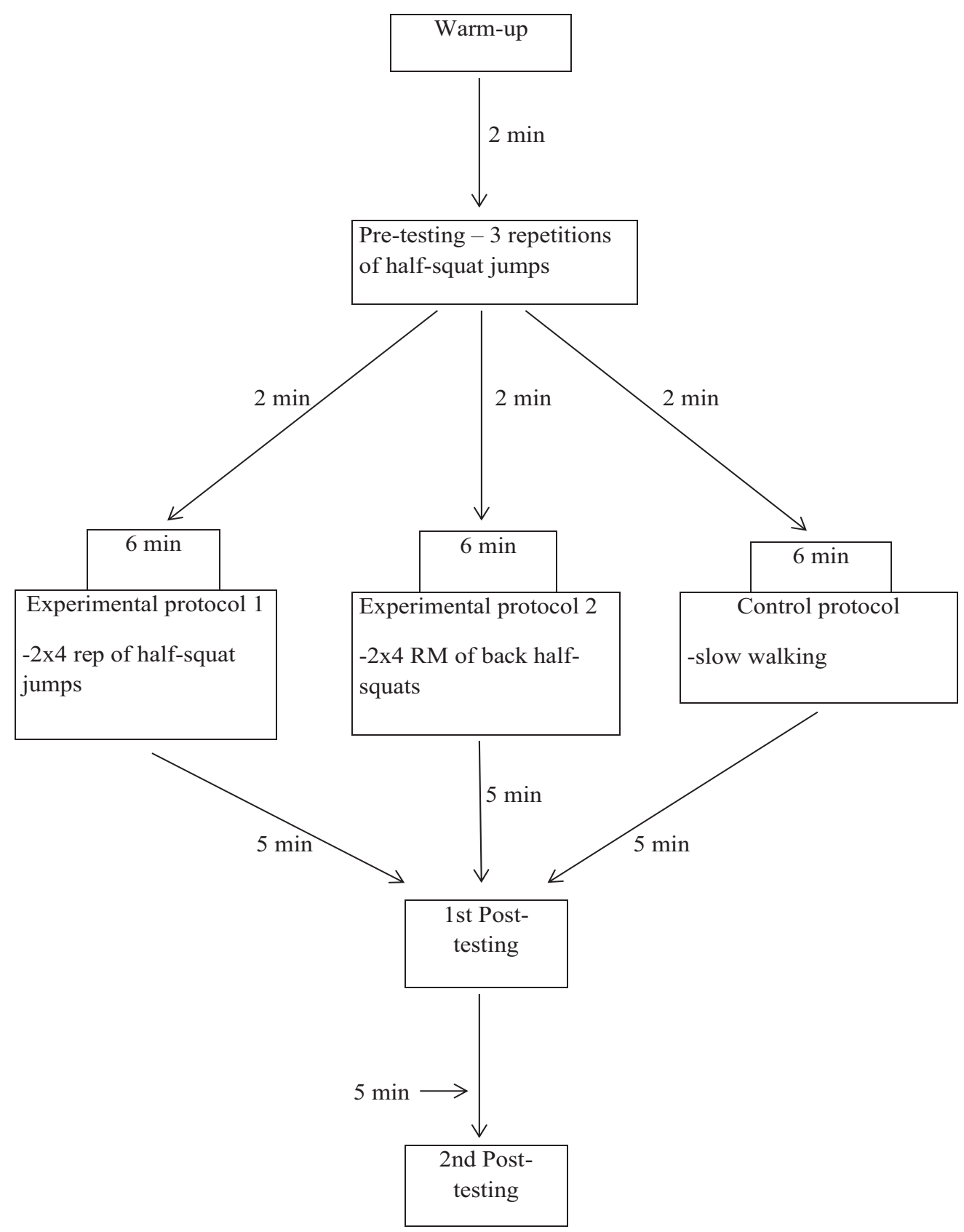

Figure 3. Schematic illustration of testing procedure during all conditioning protocols

Table 1

Half-squat jump power values (in Watts) before and after conditioning protocols

\begin{tabular}{lccccc}
\hline & & & 1st post-testing & 2nd post-testing \\
& Pre-testing & 1st post-testing & 2nd post-testing & difference & diffence \\
\hline Half-squat jump protocol & $1496.2 \pm 194.5$ & $1509.9 \pm 191.2$ & $1552.0 \pm 196.1^{\S \dagger}$ & $13.7 \pm 24.7$ & $55.8 \pm 8.9^{* *}$ \\
Half-squat protocol & $1500.7 \pm 193.2$ & $1511.7 \pm 188.2$ & $1556.7 \pm 191.2^{\S \dagger}$ & $11.0 \pm 22.1$ & $56.0 \pm 7.7^{* *}$ \\
Control protocol & $1516.7 \pm 221.8$ & $1515.6 \pm 221.3$ & $1506.9 \pm 231.1^{\dagger}$ & $-1.1 \pm 7.7$ & $-9.8 \pm 11.5^{*}$ \\
\hline
\end{tabular}

Note. 1 st post-testing difference $=$ difference between 1 st post-testing and pre-testing, 2 nd post-testing difference $=$ difference between 2nd post-testing and pre-testing. ${ }^{*} p<.05,{ }^{* *} p<.01$ : statistically significant difference between pre-testing and post-testing in the same protocol. ${ }^{\S}$ statistically significant difference between 1st and 2nd post-testing in the same protocol. "statistically significant difference in 2nd post-testing between half-squat jump protocol and control protocol; and between half-squat protocol and control protocol. Data are presented as mean \pm standard deviation. 
( $p>.99,95 \%$ confidence interval $[-7.605,9.787])$. After the second post-testing $(10 \mathrm{~min})$ participants worsened their maximum average power output and significant differences were recorded $(p=.02,95 \%$ confidence interval [1.121, 18.514]). Comparison between the 1st and 2 nd post-testing showed significant differences $(p=.049,95 \%$ confidence interval [0.030, 17.424]) (see Table 1 for values).

Comparison between experimental and control protocols for changes in maximum average power revealed no statistical significance $(F=0.115, p=.891$, $\eta_{\mathrm{p}}^{2}=.011$, power $\left.=.065\right)$ between the 1 st post-testing time points. Significant differences between experimental and control protocols between the 2 nd posttesting time points were recorded $(F=12.740, p<.001$, $\eta_{\mathrm{p}}^{2}=.56$, power $\left.=.990\right)$. Post-hoc tests revealed statistical significance $(p<.01,95 \%$ confidence interval $[16.693,73.670])$ in comparison between half-squat jumps protocol and control protocol in second posttesting (10 min). Similar results in comparison of back half-squat protocol and control protocol in the second post-testing ( $p<.001,95 \%$ confidence interval [21.329, 78.306]) were obtained. There were no significant differences when comparing half-squat jumps and back half-squats protocol in the second post-testing $(p>.99$, $95 \%$ confidence interval $[-33.124,23.851])$.

\section{Discussion}

The main finding of this study was that $11 \mathrm{~min}$ of active rest following control protocol caused a decrease in maximum average power, but a significant drop was recorded in the second post-testing, which was performed after $10 \mathrm{~min}$ rest. On the other hand, both experimental stimuli comprising 2 sets and 4 repetitions of half-squat jumps with the load equal to maximum power and 2 sets of 4RM half back-squats after 1 st and 2nd post-testing led to enhanced maximum average power and in this case significantly enhanced performance occurred in the second post-testing (10 min of rest).

A few studies exist concerning the impact of resistance exercise on lower-body peak and average power output. For example in the study by Baker (2001a) rugby league players underwent an intervention of the $60 \mathrm{~kg}$ jump squats (JS) set followed by a test series of jump squats with barbell load equal to $40 \mathrm{~kg}$, where only the highest maximum average power output was recorded. Results showed a $5.4 \%$ increase in power output with lighter load $(p \leq .05)$. The author suggests that the augmentation to the highest power output of the second JS set with lighter load in the experimental condition must have been due to the acute intervention of the heavier, $60 \mathrm{~kg}$ JS set. This suggestion is in line with previous research (Baker, 2001b; Gulich \& Schmidtbleicher, 1996; Young, Jenner, \& Griffiths, 1998) and also our findings, but it was just a case of 4RM back squats protocol. Similar results were recorded after both conditioning protocols. In the research by Talpey, Warren, and Saunders (2014) the acute effects of contrast, complex and conventional protocols on lower-body power were examined. Results showed that the conventional protocol produced significantly greater peak power than the other protocols. This is particularly the case of our study, since one of conditioning protocols was conventional (half-squat jumps protocol) and the other one was contrast (4RM half back-squat protocol). Both produced significantly greater power output. Conversely, the contrast and complex training methods are examples of unconventional practices used by coaches to enhance power output beyond the typical conventional method (Cormie, McGuigan, \& Newton, 2011; Docherty, Robbins, \& Hodgson, 2004; Sale, 2002).

Our study also included a control protocol, but some studies lacking the control group pointed to the fact that: "If no direct intervention occurred between bench throw (BT) sets, then power remained unchanged, if high repetition work bouts occurred between BT power sets, then power output is decreased and if appropriate contrasting resistance complex training strategies were interspersed between BT power sets, then power output is increased" (Baker, 2012, p. 18). According to this suggestion the inclusion of a control group in our case was appropriate because our power output testing was carried out with barbell load equal to maximum average power (strength-power protocol) and participants performed 3 repetitions in a row and 3 sets, and it could also cause potentiating or fatiguing effect when experimental stimulus was added.

Both of our conditioning protocols significantly improved power output after $10 \mathrm{~min}$ of rest and thus we can assume that potentiating effect occurred. Like we mentioned in the introduction part there are still discrepancies around the exact mechanism of PAP and also similar results in studies by other authors can be found (Gullich \& Schmidtbeicher, 1996; Sweeney, Bowman, \& Stull, 1993; Young et al., 1998). However, one novel study exists by Seitz, Trajano, Dal Maso, Haff, and Blazevich (2015) who state that not central drive but peripheral functions may contribute to the PAP effect. In their study participants performed voluntary isokinetic knee extension at $180^{\circ} \cdot \mathrm{s}^{-1}$ and electrically evoked torques as well as electromyogram data were recorded before and after 1, 4, 7, 10 and 13 min after 5 different conditioning activities (CAs). Participants performed warm-up which included extensive taskspecific practice to the point where maximal voluntary 
contractile capacity was achieved. Results show us, that inclusion of CAs elicited increases in voluntary (for $7 \mathrm{~min}$; +5.9\%) and twitch (for $4 \mathrm{~min}$; +13.5\%) torques. There were no changes in EMG M-wave after any specific CA.

In this study power output was measured before conditioning and after 5 and $10 \mathrm{~min}$ of post-conditioning. There is only one study where power output during different time intervals was examined (Liossis, Forsyth, Liossis, \& Tsolakis, 2013). The purpose of their study was to examine mean power in bench throws with barbell load equal to $30 \%$ of $1 \mathrm{RM}$, as well as to determine the preload intensity and recovery interval. Results showed that power output was significantly improved when preload stimulus of $65 \% 1 \mathrm{RM}$ (one repetition maximum) was matched with 4 min of rest ( $p=.001)$ and the same significance was observed when $85 \%$ 1RM was used when 8 min of rest was used. This was not the case of our study because significant improvement occurred after $10 \mathrm{~min}$ of rest in both protocols, but there are differences between these two studies. The first one is that in our study different exercises were performed and the second one is that external load (barbell load) in our research was higher with regard to $1 \mathrm{RM}$ in half-squat jump and back half-squat protocols, than at bench press and bench throw with regard to 1RM in the study by Liossis et al. (2013). According to this argument some studies reported that values of barbell loads, where average power output occurs during complex exercises, are closer to 1RM than the simpler exercises (Baker, Nance, \& Moore, 2001a, 2001b; Siegel, Gilders, Staron, \& Hagerman, 2002). This leads us to the conclusion that our conditioning protocols could cause a greater fatiguing effect when power output measure was performed after $5 \mathrm{~min}$ of rest, but power degradation did not occur, while a 10 min rest interval could allow full re-synthesis of phosphocreatine and also reduction of fatigue (Bevan et al., 2009). We assume that the rest interval in our study was appropriate and in line with arguments of other authors which investigated optimal recovery duration after PAP protocols. Kilduff et al. (2007) indicate that 7-12 $\mathrm{min}$ is adequate recovery time between preload and explosive activity and their statements are in line with other authors (Jo, Judelson, Brown, Coburn, \& Dabbs, 2010; Liossis et al., 2013; Mitchell \& Sale, 2011; Seitz et al., 2014; Wilson et al., 2013).

Among the limitations of this study are the low number of subjects and also missing electromyography records, therefore the potential mechanism for increasing maximum average power output can only be speculated. There is also a lack of studies where estimation of maximum average power output was measured via single linear position transducer (Garnacho-Castaño et al., 2015); however, there are studies where peak power output was measured (Cormie, Deane, \& McBride, 2007). Future studies could better examine reliability of maximum average power output via one LPT.

\section{Conclusion}

Results of this study demonstrated enhanced maximum average power output after conditioning intervention in the group of strength trained athletes representing different kinds of sports. Therefore, inclusion of such a conditioning protocol could be a useful method for improving power output in variety of sports, which require a high level of explosive power production. However, it should not be forgotten that our study included participants who were strength trained and had experience with the performed exercises.

\section{References}

Baechle, T. R., \& Earle, R. W. (2000). Essentials of strength training and conditioning (2nd ed.). Champaign, IL: Human Kinetics.

Baker, D. (2001a). A series of studies on the training of high intensity muscle power in rugby league football players. Journal of Strength and Conditioning Research, 15, 198-209.

Baker, D. (2001b). Acute and long-term power responses to power training: Observations on the training of an elite power athlete. Strength and Conditioning Journal, 23, 47-56.

Baker, D. (2003). Acute effect of altering heavy and light resistance on power output during upper-body complex power training. Journal of Strength and Conditioning Research, 17, 493-497.

Baker, D. (2012). Changes in upper body concentric mean power output resulting from complex training emphasizing concentric muscle actions. Journal of Australian Strength and Conditioning, 20(3), 15-20.

Baker, D., Nance, S., \& Moore, M. (2001a). The load that maximizes the average mechanical power output during explosive bench press throws in highly trained athletes. Journal of Strength and Conditioning Research, 15, 20-24.

Baker, D., Nance, S., \& Moore, M. (2001b). The load that maximizes the average mechanical power output during jump squats in power-trained athletes. Journal of Strength and Conditioning Research, 15, 92-97.

Bevan, H. R., Owen, N. J., Cunningham, D. J., Kingsley, M. I. C., \& Kilduff, L. P. (2009). Complex training in professional rugby players: Influence of recovery time on upperbody power output. Journal of Strength and Conditioning Research, 23, 1780-1785.

Chatzopoulos, D. E., Michailidis, C. J., Giannakos, A. K., Alexiou, K. C., Patikas, D. A., Antonopoulos, C. B., \& Kotzamanidis, C. M. (2007). Postactivation potentiation effects after heavy resistance exercise on running 
speed. Journal of Strength and Conditioning Research, 21, 1278-1281.

Cohen, J. (1988). Statistical power analysis for the behavioral sciences (2nd ed.). Hillsdale, NJ: Lawrence Erlbaum Associates.

Cormie, P., Deane, R., \& McBride, J. M. (2007). Methodological concerns for determining power output in the jump squat. Journal of Strength and Conditioning Research, 21, 424-430.

Cormie, P., McBride, J. M., \& McMaulley, G. O. (2007). The influence of body mass on calculation of power during lower-body resistance exercise. Journal of Strength and Conditioning Research, 21, 1042-1049.

Cormie, P., McGuigan, M. R., \& Newton, R. (2011). Developing maximal neuromuscular power: Part 2 - training considerations for improving maximal power production. Sports Medicine, 41, 125-146.

Docherty, D., Robbins, D., \& Hodgson, M. (2004). Complex training revisited: A review of its current status as a viable training approach. Strength and Conditioning Journal, 26(6), 52-57.

Dohoney, P., Chromiak, A. J., Lemire, D., Abadie, B., \& Kovacs, C. (2002). Prediction of one repetition maximum (1-RM) strength from a 4-6RM and a 7-10RM submaximal strength test in healthy young adult males. Journal of Exercise Physiology Online, 5(3), 54-59.

Duthie, G. M., Young, W. B., \& Aitken, D. A. (2002). The acute effects of heavy loads on jump squat performance: An evaluation of the complex and contrast methods of power development. Journal of Strength and Conditioning Research, 16, 530-538.

Fatouros, I. G., Jamurtas, A. Z., Leontsini, D., Taxildaris, K., Aggelousis, N., Kostopoulos, N., \& Buckenmeyer, P. (2000). Evaluation of plyometric exercise training, weight training, and their combination on vertical jumping performance and leg strength. Journal of Strength and Conditioning Research, 14, 470-476.

Garnacho-Castaño, M. V., López-Lastra, S., \& Maté-Muñoz, J. L. (2015). Reliability and validity assessment of a linear position transducer. Journal of Sport Science and Medicine, 14, 128-136.

Gulich, A., \& Schmidtbleicher, D. (1996). MVC-induced short-term potentiation of explosive force. New Studies in Athletics, 11(4), 67-84.

Hamar, D., Gažovič, O., \& Schickhofer, P. (1998). A simple system for strength testing and feedback monitoring of weight training. In K. Häkkinen (Ed.), International conference on weightlifting and strength training (p. 196). Jyväskyla, Finland: University of Jyväskylä.

Jeffreys, I. (2008). A review of postactivation potentiation and its application in strength and conditioning. Professional Strength and Conditioning, 12, 17-25.

Jo, E., Judelson, D. A., Brown, L. E., Coburn, J. W., \& Dabbs, N. C. (2010). Influence of recovery duration after a potentiating stimulus on muscular power in recreationally trained individuals. Journal of Strength and Conditioning Research, 24, 343-347.

Kilduff, L. P., Bevan, H. R., Kingsley, M. I. C., Owen, N. J., Bennett, M. A., Bunce, P. J., ... Cunningham, D. J. (2007). Postactivation potentiation in professional rugby players:
Optimal recovery. Journal of Strength and Conditioning Research, 21, 1134-1138.

Kyröläinen, H., Avela, J., McBride, J. M., Koskinen, S., Andersen, J. L., Sipilä, S., ... Komi, P. V. (2005). Effects of power training on muscle structure and neuromuscular performance. Scandinavian Journal of Medicine and Science in Sports, 15, 58-64.

Liossis, D. L., Forsyth, J., Liossis, C., \& Tsolakis, C. H. (2013). The acute effect of upper-body complex training on power output of martial art athletes as measured by the bench press throw exercise. Journal of Human Kinetics, 39, 167-175.

McCann, M. R., \& Flanagan, S. P. (2010). The effects of exercise selection and rest interval on postactivation potentiation of vertical jump performance. Journal of Strength and Conditioning Research, 24, 1285-1291.

Mitchell, C. J., \& Sale, D. G. (2011). Enhancement of jump performance after a 5-RM squat is associated with postactivation potentiation. European Journal of Applied Physiology, 111, 1957-1963.

Miyaguchi, K., \& Demura, S. (2008). Relationships between stretch-shortening cycle performance and maximum muscle strength. Journal of Strength and Conditioning Research, 22, 19-24.

Newton, R. U., Kraemer, W. J., \& Häkkinen, K. (1999). Effects of ballistic training on preseason preparation of elite volleyball players. Medicine \& Science in Sports \& Exercise, 31, 323-330.

Paasuke, M., Ereline, J., \& Gapeyevea, H. (1996). Twitch potentiation capacity of plantar-flexor muscles in endurance and power athletes. Biology of Sport, 15, 171-178.

Radcliff, J. C., \& Radcliff, J. L. (1996). Effects of different warm-up protocols on peak power output during a single response jump task. Medicine \& Science in Sports \& Exercise, 28(Suppl. 5), 189.

Rassier, D. E., \& Macintosh, B. R. (2000). Coexistence of potentiation and fatigue in skeletal muscle. Brazilian Journal of Medicine and Biology Research, 33, 499-508.

Sale, D. G. (2002). Postactivation potentiation: Role in human performance. Exercise and Sport Science Review, 30, 138-143.

Seitz, L. B., de Villarreal, E. S., \& Haff, G. G. (2014). The temporal profile of postactivation potentiation is related to strength level. Journal of Strength and Conditioning Research, 28, 706-715.

Seitz, L. B., Trajano, G. S., Dal Maso, F., Haff, G. G., \& Blazevich, A. J. (2015). Postactivation potentiation during voluntary contractions after continued knee extensor task-specific practice. Applied Physiology, Nutrition, and Metabolism, 40, 230-237.

Siegel, J. A., Gilders, R. M., Staron, R. S., \& Hagerman, F. C. (2002). Human muscle power output during upper and lower body exercises. Journal of Strength and Conditioning Research, 16, 173-178.

Sweeney, H. L., Bowman, B. F., \& Stull, J. T. (1993). Myosin light chain phosphorylation in vertebrate striated muscle: Regulation and function. American Journal of Physiology, 264, 1085-1095.

Talpey, W. S., Warren, B. Y., \& Saunders, N. (2014). The acute effects of conventional, complex, and contrast 
protocols on lower-body power. Journal of Strength and Conditioning Research, 28, 361-366.

Tendo Power Analyzer Weightlifting: User's Guide. (2014). Trenčín, Slovak Republic: Tendo Sports Machines.

Tillin, A., \& Bishop, D. (2009). Factors modulating post-activation potentiation and its effect on performance of subsequent explosive activities. Sports Medicine, 39, 147-166.

Wilson, J. M., Duncan, N. M., Marin, P. J., Brown, L. E., Loenneke, J. P., Wilson, S. M. C., ... Ugrinowitsch, C. (2013). Meta-analysis of postactivation potentiation and power: effects of conditioning activity, volume, gender, rest periods, and training status. Journal of Strength and Conditioning Research, 27, 854-859.

Young, W. B., Jenner, A., \& Griffiths, K. (1998). Acute enhancement of power performance from heavy load squats. Journal of Strength and Conditioning Research, 12, 82-84.

Zemková, E., Jeleň, M., Kováčiková, Z., Ollé, G., Vilman, T., \& Hamar, D. (2014). Enhancement of peak and mean power in concentric phase of resistance exercises. Journal of Strength and Conditioning Research, 28, 2919-2926. 